
randomly selected papers on which Mertelsmann - but not Herrmann — was listed as a co-author. It asked the authors for original patient data to allow them to analyse tables and graphs.

According to Rapp, sufficient original data were provided to fully analyse only one paper, published in Blood in 1994 (volume 84, 1421). This paper investigated a technique to help cancer patients recover from the bone-marrow damage that reduces blood-cell counts following high-dose chemotherapy.

The paper looked at the rate of recovery of blood cells when the patients' own peripheral-blood progenitor cells, taken before chemotherapy, were transplanted back, either unseparated or purified. The paper concluded that recovery was rapid and complete in either case.

But the task force's report says the paper contained many "irregularities and indications that data had been improperly handled". Rapp told Nature that the published graphs describing blood-cell recovery omitted data on a significant proportion of the patients. "If you mis-portray clinical data in important journals you may encourage others to adopt a practice that could put patients at risk," he says.

In response to the task force's findings, the DFG has launched a formal investigation of Mertelsmann and of Lothar Kanz and Wolfram Brugger, respectively professor and senior researcher at the University of Tübingen, and co-authors of the Blood paper.

The University of Freiburg has also opened an internal investigation into the allegations. Kanz declined this week through his lawyers to comment on the investigation; the two other authors did not respond to several requests from Nature to discuss the issues raised by the task force in its report.

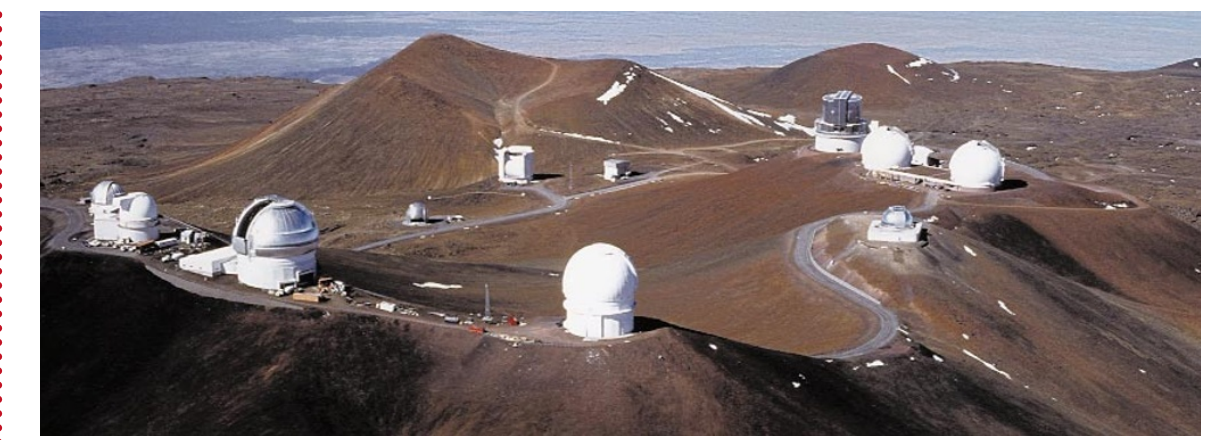

Looking up: expansion plans for the facilities at Mauna Kea have been welcomed by astronomers.

\title{
Hawail reaches for the stars with astronomy master plan
}

\section{Rex Dalton \& Alison Abbott}

A long-awaited master plan for the future development of astronomy projects on Mauna Kea in Hawaii was approved last week by the University of Hawaii. The agreement comes after two years of negotiations with native Hawaiian cultural groups and environmentalists and a last-minute decision to drop two of the planned facilities.

At the same time, the university has announced that its three-year search for a new director for its Institute of Astronomy is over. Rolf-Peter Kudritzki, currently director of the Institute for Astronomy and Astrophysics at the University of Munich, will take up his new post in October.

Kudritzki says that Mauna Kea has "enormous scientific potential because it is host to so many international observatories".

The master plan to set up an 'astronomy precinct' within the Mauna Kea Science Reserve, and the recruitment of Kudritzki, will allow Hawaii to move forward with a number of plans for expansion and improvements at Mauna Kea. The site is currently home to a number of major facilities, such as the Keck telescope.

Under the plan, three new facilities will be built, five of the existing 13 facilities will be redeveloped, and two of the existing facilities will be expanded.

Native Hawaiians have expressed concern that telescopes and other facilities built near Mauna Kea's 14,000-foot-tall peak would disturb land on which traditional gods are believed to live. Environmentalists have raised concerns about possible damage.

As part of the compromise agreement worked out, the university has cancelled plans for a 4- to 12-metre telescope and an optical/infrared interferometer facility.

In response to local concerns, the master plan calls for an advisory group of native Hawaiians to have a say in future expansion. But native Hawaiians themselves remain sharply divided on Mauna Kea astronomy development. Some leaders have endorsed the master plan, but others continue to threaten legal action to block it.

Kudritzki says the "master plan presents an appropriate balance between the concerns of ecology, religion and astronomy".

\section{Oxford epidemiologist wins apology for promotion slur}

\section{Natasha Loder, London}

Sunetra Gupta, the University of Oxford epidemiologist wrongly accused of having won support for a readership post through a relationship with her head of department (see Nature 403, 353; 2000), has received a retraction and an apology from Roy Anderson, the chair of the appointment committee.

Anderson wrote to Gupta last week unreservedly withdrawing an allegation for which he said there was "no foundation in truth whatsoever and which I accept I never should have made". It has taken Gupta eight months to get the retraction, during which time, she says, she received little support from the university, which she felt had tried to brush the situation under the carpet.

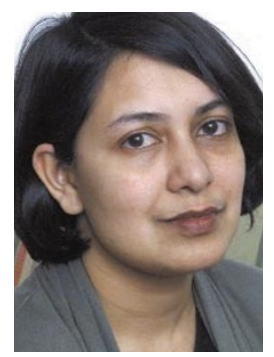

Gupta: waited eight months for apology.
Gupta says that Anderson's comments about her were "totally unacceptable and could not be allowed". She rejects as "highly offensive" criticism from some members of the department of zoology who say she was manipulated into complaining.
The university has already upheld complaints that Anderson had intimidated members of Gupta's appointment committee. His behaviour also led to complaints about his management of the Wellcome Trust Centre for the Epidemiology of Infectious Diseases (see Nature 403, 695; 2000), and ultimately his resignation from the centre, from Oxford University and as governor of the Wellcome Trust.

In his letter to Gupta, Anderson says he was under "a great deal of personal stress at the time". Anderson has also agreed to pay Gupta's legal costs and to make a donation to charity. 